\title{
A APLICAÇÃO DO FORMULÁRIO DE LIÇÕES APRENDIDAS NAS OPERAÇÕES DE GARANTIA DA LEI E DA ORDEM (GLO)
}

\author{
Rogério Oliveira Santana ${ }^{1}$ \\ 1 Pós-Graduado em Gestão de Organização Militar de Inteligência pela Escola de Inteligência Militar do Exército (EsIMEx), \\ rogerio1978@yahoo.com.br
}

\begin{abstract}
Resumo
Este trabalho analisa a aplicação do formulário de lições aprendidas nas operações de Garantia da Lei e da Ordem (GLO). Tal abordagem se faz necessária para que essa ferramenta da qualidade possa contribuir para que em outras operações não ocorram os mesmos erros cometidos no pretérito. A finalidade desta pesquisa é apresentar a funcionalidade da Sistemática de Acompanhamento Doutrinário e Lições Aprendidas (SADLA), do Exército Brasileiro, na execução de uma Operação de GLO. Este intendo será conseguido através da revisão bibliográfica, pesquisa documental e resultados da pesquisa de campo. Demonstrou-se que os conhecimentos lançados na SADLA aumentam a eficiência da tropa durante uma Operação de GLO, porém deve ser de responsabilidade dos chefes de célula o lançamento dos dados na SADLA.
\end{abstract}

Palavras-chave: Garantia da Lei e da Ordem. Sistemática de Acompanhamento Doutrinário e Lições Aprendidas. Exército Brasileiro.

\section{Resumen}

Este trabajo analiza la aplicación del formulario de lecciones aprendidas en las operaciones de Garantía de la Ley y de la Orden (GLO). Este enfoque se hace necesario para que esta herramienta de calidad pueda contribuir a que en otras operaciones no ocurran los mismos errores cometidos en el pretérito. La finalidad de esta investigación es presentar la funcionalidad de la Sistemática de Acompañamiento Doctrinario y Lecciones Aprendidas (SADLA), del Ejército Brasileño, en la ejecución de una Operación de GLO. Este intendente será logrado a través de la revisión bibliográfica, la investigación documental y resultados de la búsqueda de campo. Se ha demostrado que el conocimiento que se lanza en SADLA aumenta la eficiencia de las tropas durante una operación de GLO, pero debería ser responsabilidad de los jefes de célula lanzar los datos en SADLA.

Palabras clave: Garantía de la Ley y de la Orden. Sistemática de Acompañamiento Doctrinario y Lecciones Aprendidas. Ejército brasileño.

(C)UNIS-MG. All rights reserved.

How to cite this article:

SANTANA, Rogério Oliveira. A APLICAÇÃO DO FORMULÁRIO DE LIÇÕES APRENDIDAS NAS OPERAÇÕES DE GARANTIA DA LEI E DA ORDEM (GLO). Interação, Varginha, MG, v. 21, p. 30 - 43, 2019. ISSN 1517-848X / ISSN $2446-9874$. Disponível em: http://periodicos.unis.edu.br/index.php/interacao/article/view/277.

DOI: https://doi.org/10.33836/interacao.v21i2.277

\section{INTRODUÇÃO}

Atualmente, na era do conhecimento, as experiências e as lições aprendidas geradas pelos profissionais, depois de processadas, produzem um conhecimento e consolidam as boas práticas. 
A APLICAÇÃO DO FORMULÁRIO DE LIÇÕES APRENDIDAS NAS OPERAÇÕES DE GARANTIA DA LEI E DA ORDEM (GLO).

Essa gestão do conhecimento é fundamental para o crescimento de qualquer organização ou instituição.

A importância de um banco de dados de lições aprendidas é fundamental para todas as instituições e empresas, buscando evitar erros e reduzir riscos e custos durante a execução de um processo ou projeto.

A Sistemática de Acompanhamento Doutrinário e Lições Aprendidas (SADLA), do Exército Brasileiro, na execução de uma Operação de GLO ainda é pouco empregada. A ferramenta de tecnologia da informação, hospedada no site do Comando de Operações Terrestre (COTER) proporciona que os militares possam contribuir com suas lições aprendidas e possam consultar conhecimento já validado. Desta forma, o Exército Brasileiro disponibiliza um banco de dados de fácil utilização com a finalidade de aumento da sua eficiência e operacionalidade.

No ano de 2017, o Exército Brasileiro publicou a Portaria no 104-COTER, de 19 de dezembro de 2017, que aprovou as Instruções Reguladoras da Sistemática de Acompanhamento Doutrinário e Lições Aprendidas (EB70-IR-10.007), 3ạ Edição, 2017.

Segundo a Portaria no 104-COTER, de 19 de dezembro de 2017, a SADLA foi criada para consolidar as experiências doutrinárias oriundas da instrução individual e coletiva, dos exercícios de adestramento e do emprego da Força em operações militares, visando à evolução contínua da Doutrina Militar Terrestre (DMT).

A sistemática busca aproveitar tudo o que possa interferir positivamente no preparo e/ou no emprego, por meio de lições aprendidas e melhores práticas.

Este trabalho procura analisar como esta ferramenta de tecnologia da informação pode contribuir para a formação de um banco de dados de lições aprendidas, concluindo sobre como aumentar a utilização da SADLA pelos planejadores das operações de GLO.

Tal abordagem se justifica pela relevância pessoal, profissional e social, na medida em que busca a qualidade e eficiência nas operações de GLO, propondo um importante assessoramento para o planejamento e execução das operações e garantindo melhores resultados para a sociedade (clientes), fazendo uso de experiência pessoal do autor.

É uma pesquisa básica, com objetivo de gerar conhecimentos que sirvam de subsídios para que o COTER, as Organizações Militares e as Escolas de Formação do Exército possam estimular a utilização da SADLA em operações e em planejamentos de Estado-Maior.

Este intento será conseguido mediante revisão bibliográfica e documental, utilizando-se de fontes de pesquisas anteriores, publicações sobre o tema e pesquisa de campo. De natureza 
qualitativa, com a finalidade de apresentar um relatório conclusivo, a partir de interpretações e análises do roteiro aplicado.

\section{GESTÃO DO CONHECIMENTO}

Segundo Probst, Raub e Romhardt (2002, p. 16), "para sobreviver e competir na sociedade do conhecimento, as empresas devem aprender a administrar os seus ativos intelectuais, já que o conhecimento é o único recurso que aumenta com o uso". Para tanto, o Exército Brasileiro implementou a SADLA para administrar os ativos intelectuais através de uma ferramenta de tecnologia da informação.

Por criação do conhecimento organizacional Nonaka e Takeuchi (1997, p. 01) compreendem "a capacidade de uma empresa de criar novo conhecimento, difundi-lo na organização como um todo e incorporá-lo a produtos, serviços e sistemas".

Segundo Scatolin (2015), a criação do conhecimento organizacional é a chave para as formas características com que as empresas japonesas inovam. Elas são peritas em fomentar a inovação de forma contínua, incremental e em espiral.

De acordo com Nonaka e Takeuchi (1997, p. 04) "o que é singular na forma das empresas japonesas proporcionarem inovações contínuas é a ligação entre o externo e o interno". É essa dupla atividade, interna e externa, que abastece a inovação contínua dentro das empresas japonesas.

Por Nonaka e Takeuchi (2008):

o conhecimento tácito em duas dimensões. A primeira dimensão é técnica e abrange um tipo de capacidade informal e difícil de definir. São as habilidades capturadas no termo "know-how". Um artesão, por exemplo, desenvolve uma riqueza de habilidades, mas frequentemente é incapaz de articular os princípios técnicos ou científicos subjacentes ao que sabe. Já a segunda dimensão é a cognitiva. Isto significa que o conhecimento tácito consiste em esquemas, modelos mentais, crenças e percepções tão arraigadas que os tomamos como certos. A dimensão cognitiva do conhecimento tácito reflete nossa imagem da realidade (o que é) e nossa visão do futuro (o que deveria ser). Apesar de não poderem ser articulados muito facilmente, esses modelos implícitos moldam a forma com que percebemos o mundo a nossa volta.

Ainda segundo Nonaka e Takeuchi (2008), uma organização por si mesma não pode criar conhecimento sem a iniciativa do indivíduo e a interação que ocorre dentro do grupo, ou seja, o Exército Brasileiro necessita da alimentação das lições aprendidas por parte do seu púbico interno, para aperfeiçoamento das suas atividades operacionais e logísticas. 


\title{
3 AS INSTRUÇÕES REGULADORAS DA SADLA (EB70-IR-10.007), PUBLICADAS NO BOLETIM DO EXÉRCITO NR 52/2017, DE 29 DE DEZEMBRO DE 2017
}

As Instruções Reguladoras em vigor, publicadas no Boletim do Exército Nr 52/2017, de 29 de dezembro de 2017, têm por finalidade orientar a Sistemática de Acompanhamento Doutrinário e Lições Aprendidas (SADLA), conforme o estabelecido nas Instruções Gerais para o Sistema de Doutrina Militar Terrestre (SIDOMT) (EB10-IG-01.005).

As Instruções Reguladoras publicadas assim definem a SADLA:

\begin{abstract}
a SADLA é o processo que reúne os conhecimentos militares disponíveis por meio das experiências doutrinárias oriundas da instrução individual e coletiva, dos exercícios de adestramento e do emprego da Força em operações militares, visando a evolução contínua da doutrina militar terrestre (DMT). A SADLA busca aproveitar tudo o que possa interferir positivamente no preparo e/ou no emprego, por meio de lições aprendidas (Lç Aprd) e melhores práticas (Mlh Prat). (p. 9).
\end{abstract}

Segundo as IR (EB70-IR-10.007), a SADLA possui a seguinte estrutura: órgão indutor, órgão Central, gestor e integrantes. Neste último grupo estão inseridos os autores de contribuições individuais e os oficiais de doutrina e lições aprendidas (ODLA), ou seja, a base de alimentação do formulário de lições aprendidas das operações de Garantia da Lei e da Ordem.

Segundo as IR (EB70-IR-10.007):

o Conhecimento para Interesse da Doutrina (CID) é um dado de caráter técnico-operacional, decorrente do exercício da profissão militar (experiências individuais ou coletivas), de relatórios, das atividades de instrução, de adestramento e, principalmente, de situações de emprego da Força Terrestre (F Ter), que deve ser submetido a uma análise para identificar uma lição aprendida ou uma melhor prática. (p. 10). 


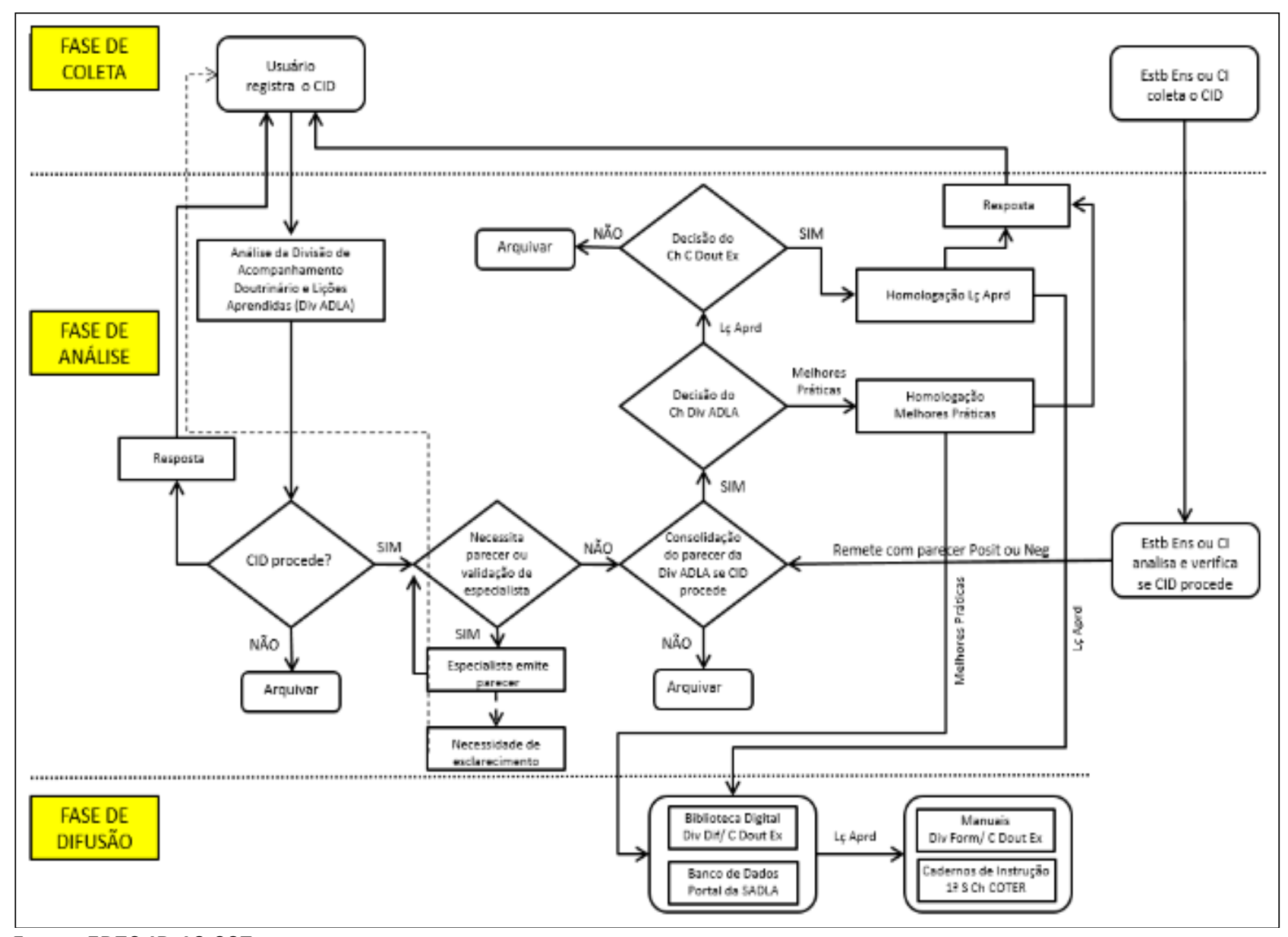

Fonte: EB70-IR-10.007

Ainda de acordo com as IR (EB70-IR-10.007), os contribuintes individuais podem acessar o Portal de Lições Aprendidas, através do endereço eletrônico https://sadla.coter.eb.mil.br/index.php/access, com os mesmos dados de usuário e senha utilizados para acessar o sistema de informações de pessoal do Departamento Geral do Pessoal (DGP), submetendo suas propostas, editando, acompanhando seu andamento e consultando outras em processamento, além de ter acesso a lições aprendidas e melhores práticas já homologadas pelo Centro de Doutrina do Exército, subordinado ao COTER.

\section{MATERIAL E MÉTODO}

A revisão da literatura existente é fundamental para amparar o conhecimento a ser apresentado ao final deste artigo científico. O material utilizado para consolidação do artigo científico são os manuais existentes e as portarias publicadas, constantes das referências bibliográficas, além de livros e artigos científicos publicados. 
Segundo Gil (1999), a pesquisa bibliográfica é a utilização de conhecimento retirado de pesquisas e tem o objetivo de ratificar o que está sendo escrito no presente artigo.

A pesquisa de campo realizada tem por objetivo levantar sugestões e apresentar um panorama de como estão sendo realizadas as operações de GLO pelo Exército Brasileiro. O universo de consulta é de oficiais e praças, que realizaram ou não operações de GLO. Desta forma, os dados obtidos ratificam o conhecimento científico apresentado no presente artigo.

Segundo Fuzzi (2004), a pesquisa de campo exige também a determinação das técnicas de coleta de dados mais apropriadas à natureza do tema e, ainda, a definição das técnicas que serão empregadas para o registro e análise.

A pesquisa de campo procede à observação de fatos e fenômenos exatamente como ocorrem no real, à coleta de dados referentes aos mesmos e, finalmente, à análise e interpretação desses dados, com base numa fundamentação teórica consistente, objetivando compreender e explicar o problema pesquisado.

É uma pesquisa aplicada, com objetivo de gerar conhecimentos para aplicação, utilização e consequências práticas imediatas, dirigida à solução de um problema específico, que é sobre como aumentar a utilização da SADLA pelos planejadores das operações de GLO.

É uma pesquisa tipo exploratória, bibliográfica e documental, com objetivo de levantar fontes de pesquisas para subsidiar sugestões para a melhor funcionalidade da SADLA, utilizando-se de fontes de pesquisas anteriores e publicações existentes sobre o tema.

Ainda, é uma pesquisa qualitativa, com a finalidade de apresentar um relatório conclusivo, a partir de interpretações e análises do roteiro aplicado.

\section{RESULTADO E DISCUSSÕES}

\subsection{As lições aprendidas existentes na SADLA em operações de GLO}

Conforme o Exército Brasileiro (Brasil, 2017, p. 1):

oficiais e sargentos do EB são formados de acordo com um de Disciplina (PLADIS) e dentro do círculo hierárquico não há uma diferença discrepante no que tange ao conhecimento adquirido em suas formações. Mesmo os cabos e soldados, que são formados no Corpo de Tropa, têm sua instrução padronizada pelos Programas-Padrão de Instrução de acordo com a natureza de sua Organização Militar (OM) e sua função. Infere-se, dessa forma, que, dentro de um mesmo nível hierárquico, todos têm, a princípio, o mesmo conhecimento sobre os assuntos profissionais. Todos estão, dessa forma, capacitados a reconhecer as causas de sucesso ou fracasso de uma atividade, bem como apontar os aspectos que devem ser ratificados ou retificados. 
A importância do registro de lições aprendidas é importante para evitar que erros voltem a acontecer e que acertos sejam considerados como melhores práticas, para serem seguidas durante as operações a serem realizadas.

A técnica de consolidação de dados de lições aprendidas é fundamental para que o Exército Brasileiro possa tomar conhecimento das diversas práticas e possa analisá-las com apoio de especialistas, para que outros militares possam fazer uso do conhecimento armazenado no banco de dados.

O objetivo da consolidação dos lançamentos existentes no banco de dados da SADLA no período de 2015 até 2018 permite fazer uma análise sobre o nível de alimentação do sistema após a realização das operações de GLO.

Analisando o banco de dados existente, dos 269 lançamentos existentes, podemos constatar que todas as melhores práticas cadastradas, foram lançadas no período de 19 a 28 de fevereiro de 2018. Deste total, 75 lançamentos, ou seja, 38\% são direcionados especificamente para a atividade de Garantia da Lei e da Ordem (GLO).

Gráfico 1 - Lançamentos de melhores praticas na SADLA

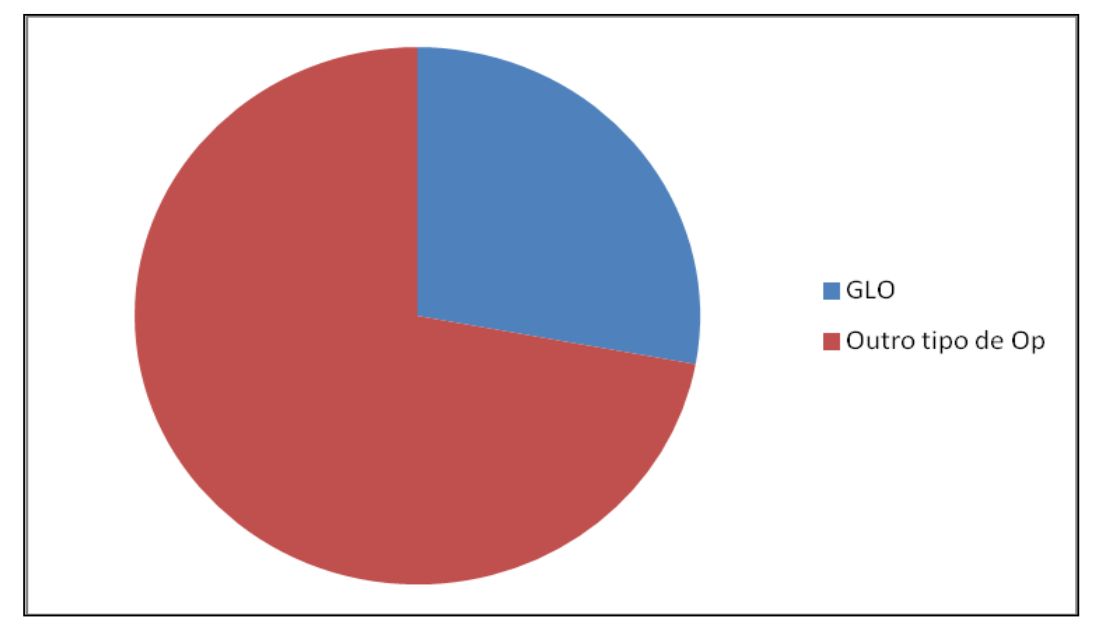

Fonte: o autor com base nos dados da SADLA de setembro de 2018.

Para subsidiar uma operação de GLO, com melhores práticas já validadas pelo Comando de Operações Terrestre (COTER), o banco de dados já disponibiliza conhecimentos de ambiente urbano, de logística de pessoal, material e saúde, de inteligência, de comunicações e guerra eletrônica, de operações psicológicas, de planejamento de Estado-Maior, de educação e ensino, de aviação e de tropa blindada. 
A APLICAÇÃO DO FORMULÁRIO DE LIÇÕES APRENDIDAS NAS OPERAÇÕES DE GARANTIA DA LEI E DA ORDEM (GLO).

Gráfico 2 - Tipos de conhecimento de GLO cadastrados na SADLA.

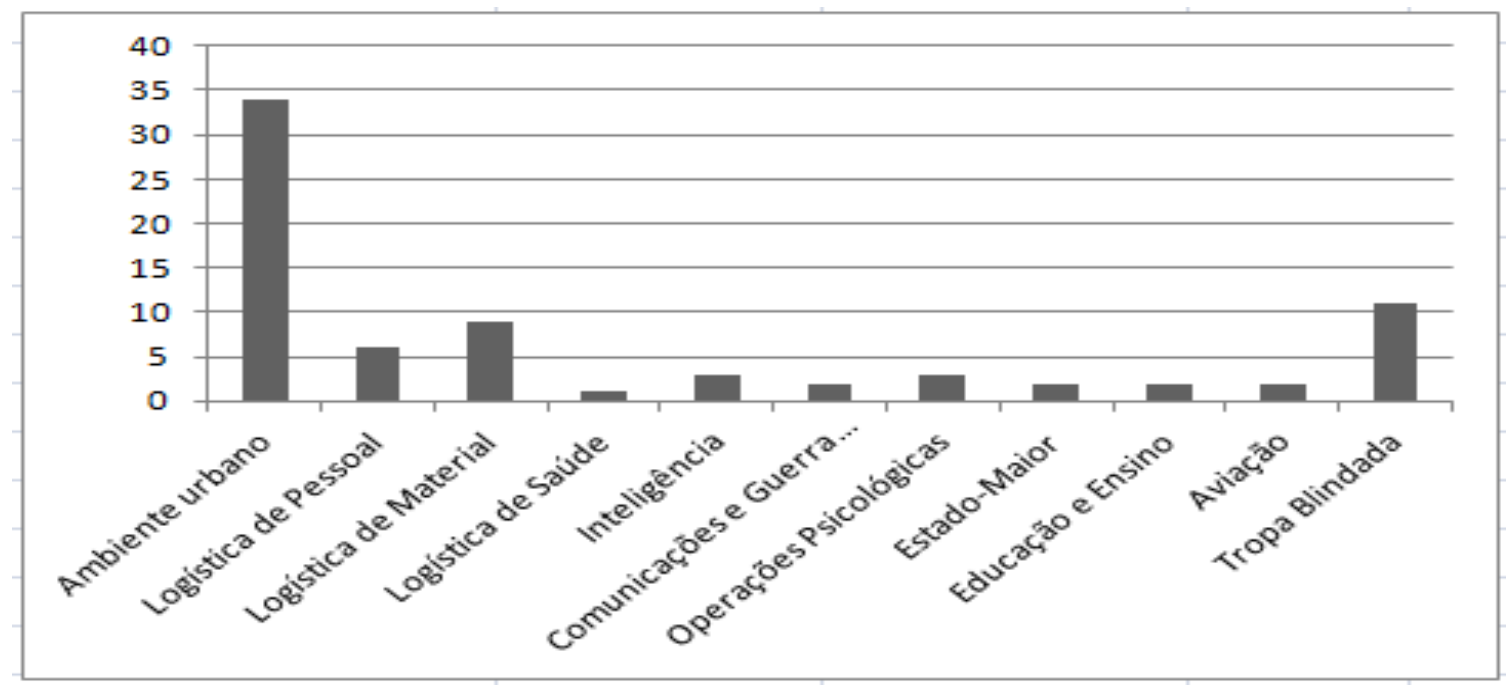

Fonte: o autor com base nos dados da SADLA de setembro de 2018.

Observa-se no gráfico 2 que o ambiente urbano houve uma quantia relevante das análises realizadas, superior à 30 , sendo seguida por tropa blindada e logística de material, nos tipos de conhecimentos disponíveis cadastrados no sistema.

\subsection{Pesquisa de campo}

No mês de setembro de 2018, foi realizada uma pesquisa de campo, com 100 (cem) militares do Exército Brasileiro com a finalidade de levantar uma amostragem de militares que já participaram de operações de GLO, que já participaram de reuniões pós-ação e sobre o seu conhecimento sobre a SADLA.

Gráfico 3 - Universo de pesquisa de campo.

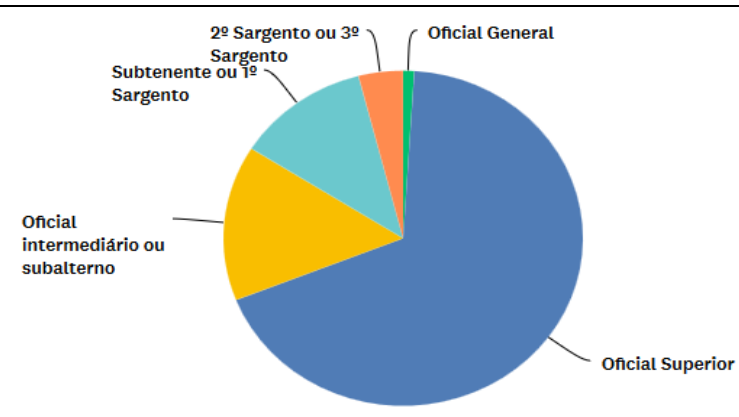

\begin{tabular}{|c|c|c|}
\hline OPÇÕES DE RESPOSTA & RESPOSTAS & s \\
\hline Offcial General & $1,00 \%$ & 1 \\
\hline Offcial Superior & $68,00 \%$ & 68 \\
\hline Offial intermediário ou subalterno & $15,00 \%$ & 15 \\
\hline - Subtenente ou 19 Sargento & $12,00 \%$ & 12 \\
\hline - 20 Sargento ou 3 Sargento & $4,00 \%$ & 4 \\
\hline TOTAL & & 100 \\
\hline
\end{tabular}

Fonte: o autor. 
Na pesquisa observa-se que 83 \% do universo já participou de reunião de Análise Pós Ação (APA), após a realização de uma Operação de GLO, ou seja, fica evidenciado que é comum que ocorram essas reuniões para consolidação das lições aprendidas durante a operação realizada.

Gráfico 4 - Universo de militares que já participaram de reunião de APA e que confeccionaram relatório da operação.

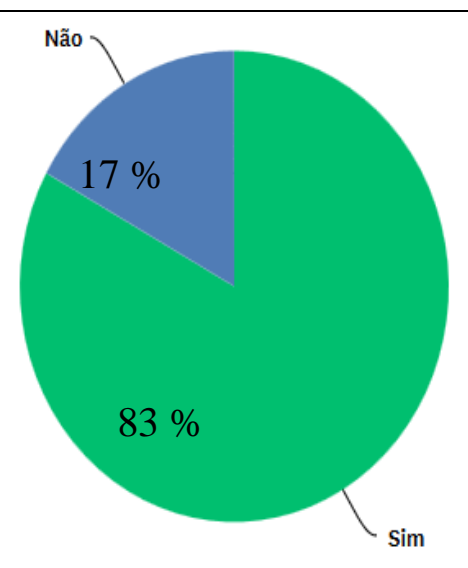

Fonte: o autor.

A pesquisa atestou que durante as reuniões de APA realizadas, $77 \%$ do universo declarou que em algum momento da APA, são abordadas as lições aprendidas. Desta forma, fica caracterizada a necessidade de uma normatização dessas reuniões, para que contemplem essas lições aprendidas após todas as operações realizadas e que as Organizações Militares envolvidas, lancem na SADLA as suas respectivas experiências colhidas durante o emprego operacional e logístico.

Gráfico 5 - Universo que declarou que durante a realização das reuniões de APA é abordado o tema de lições aprendidas.

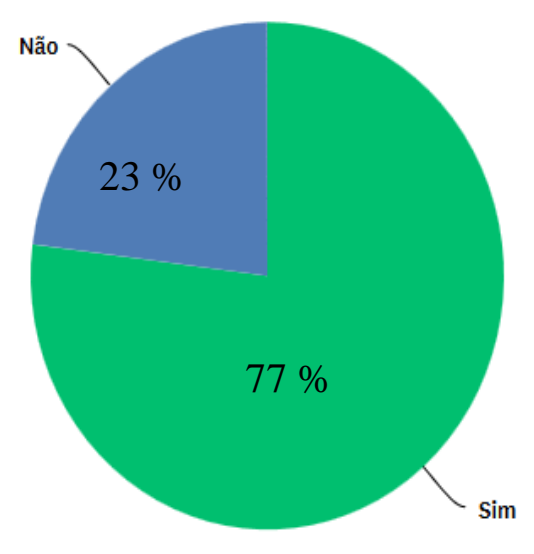

Fonte: 0 autor.

A pesquisa atestou que, na grande maioria das operações realizadas de GLO, são confeccionados relatórios da preparação e execução da operação, com 86 \% do efetivo afirmando 
que os relatórios são confeccionados (gráfico da esquerda), no entanto somente $48 \%$ responderam que utilizaram estes relatórios em operações futuras, 36 \% não souberam dizer e 16 \% afirmaram que o relatório foi arquivado e não utilizado em operações futuras (gráfico da direita).

Gráfico 6 - Universo que declarou que durante a realização das reuniões de APA é abordado o tema de lições aprendidas.

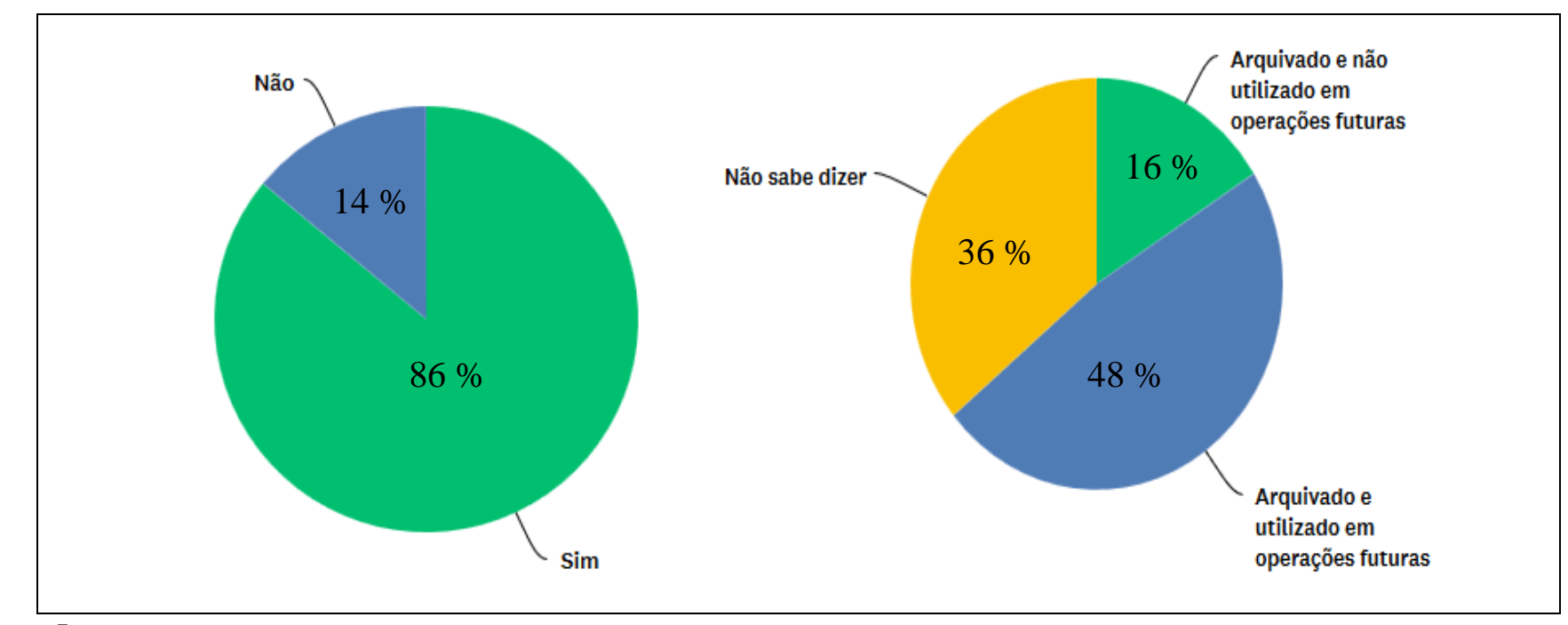

Fonte: o autor.

Sobre a SADLA, somente $45 \%$ (gráfico da esquerda) do universo pesquisado afirmou conhecer a ferramenta de tecnologia da informação, responsável pela consolidação e validação das lições aprendidas e melhores práticas, sendo que somente 9 \% (gráfico da direita) já utilizaram a SADLA como instrumento de consulta antes e durante a realização das operações de GLO, o que configura uma necessidade de regulamentação de instruções de quadros nas Organizações Militares e o necessário estabelecimento de metas anuais para cada Comando Militar de Área.

Gráfico 7 - Universo que declarou conhecer a SADLA e que já utilizaram para consulta antes e durante a realização das operações de GLO.

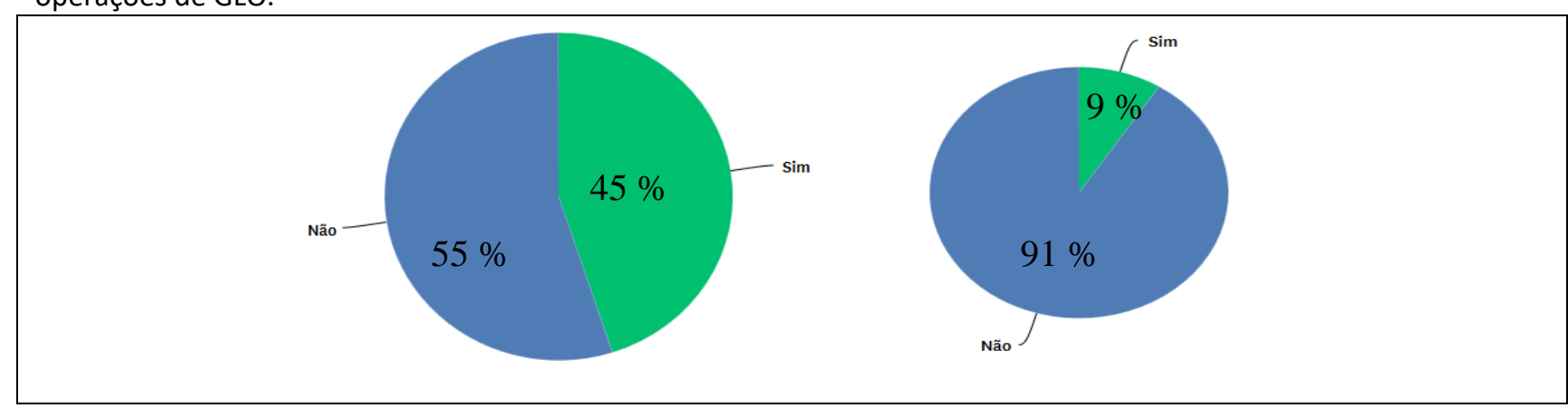

Fonte: o autor.

O universo de $92 \%$ (gráfico da esquerda) da pesquisa realizada declarou acreditar que os conhecimentos lançados na SADLA aumentam a eficiência da tropa durante uma Operação de GLO, já 76 \% (gráfico da direita) declarou acreditar que a 3a Seção de um Grande Comando/Grande 
Unidade/Organização Militar consegue coordenar o lançamento das lições aprendidas na SADLA, após a realização da APA.

Gráfico 8 - Universo que declarou acreditar que os conhecimentos da SADLA aumentam a eficiência da tropa e que a 3ạ Seção (operações) consegue coordenar o lançamento na SADLA.
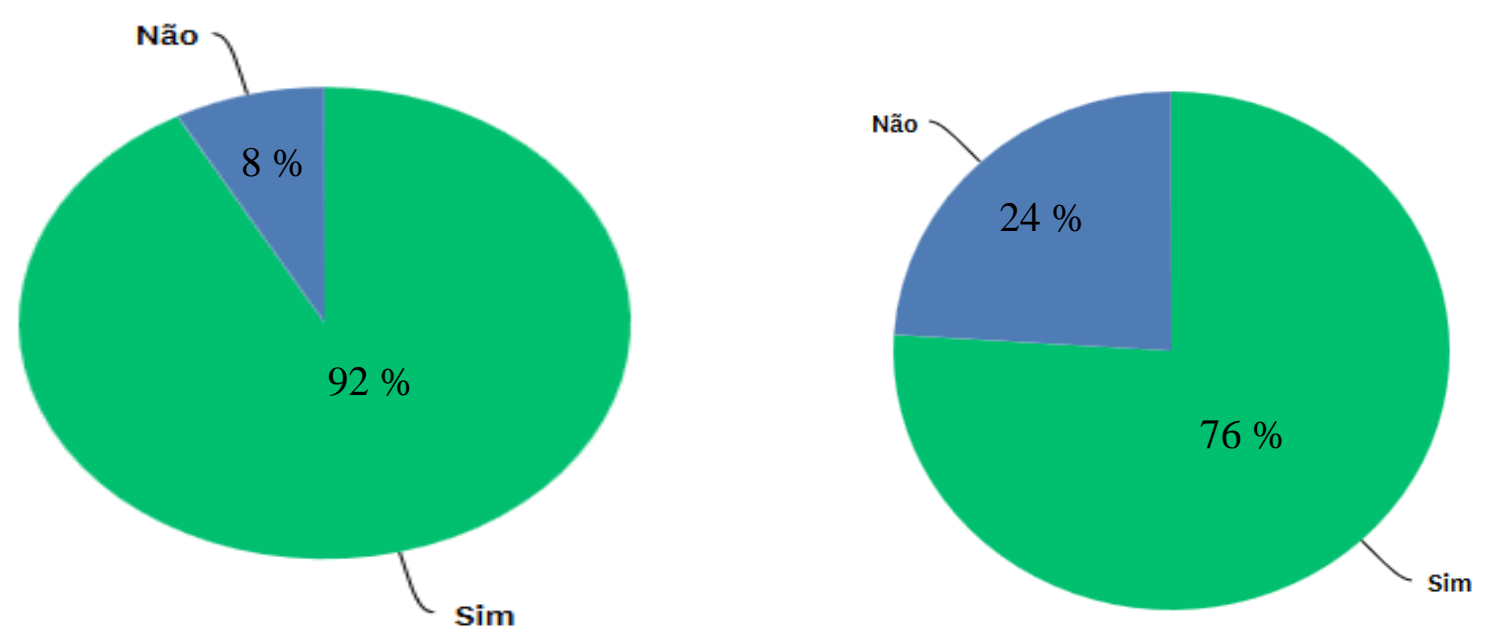

Fonte: o autor.

O universo de 50 \% afirmou que todos os chefes de seção ou célula em operações devem ser os responsáveis por consultar o banco de dados da SADLA antes e durante uma Operação de GLO, ou seja, não há necessidade de se criar uma determinação para a Seção de Operações.

De acordo com a EB70-IR-10.007, no Art 3o, que trata da estrutura da SADLA já está prevista a função de Oficial de Doutrina e Lições Aprendidas (ODLA). No Art 28으, estão previstas as atribuições das Organizações Militares (OM), tendo em seu inciso II, a diretriz para que o ODLA oriente as propostas de lições aprendidas ou de melhores práticas dos militares subordinados, quando necessário. 
Gráfico 9 - Universo que declarou quem deve ser o responsável por consultar a SADLA antes e durante as operações de GLO.

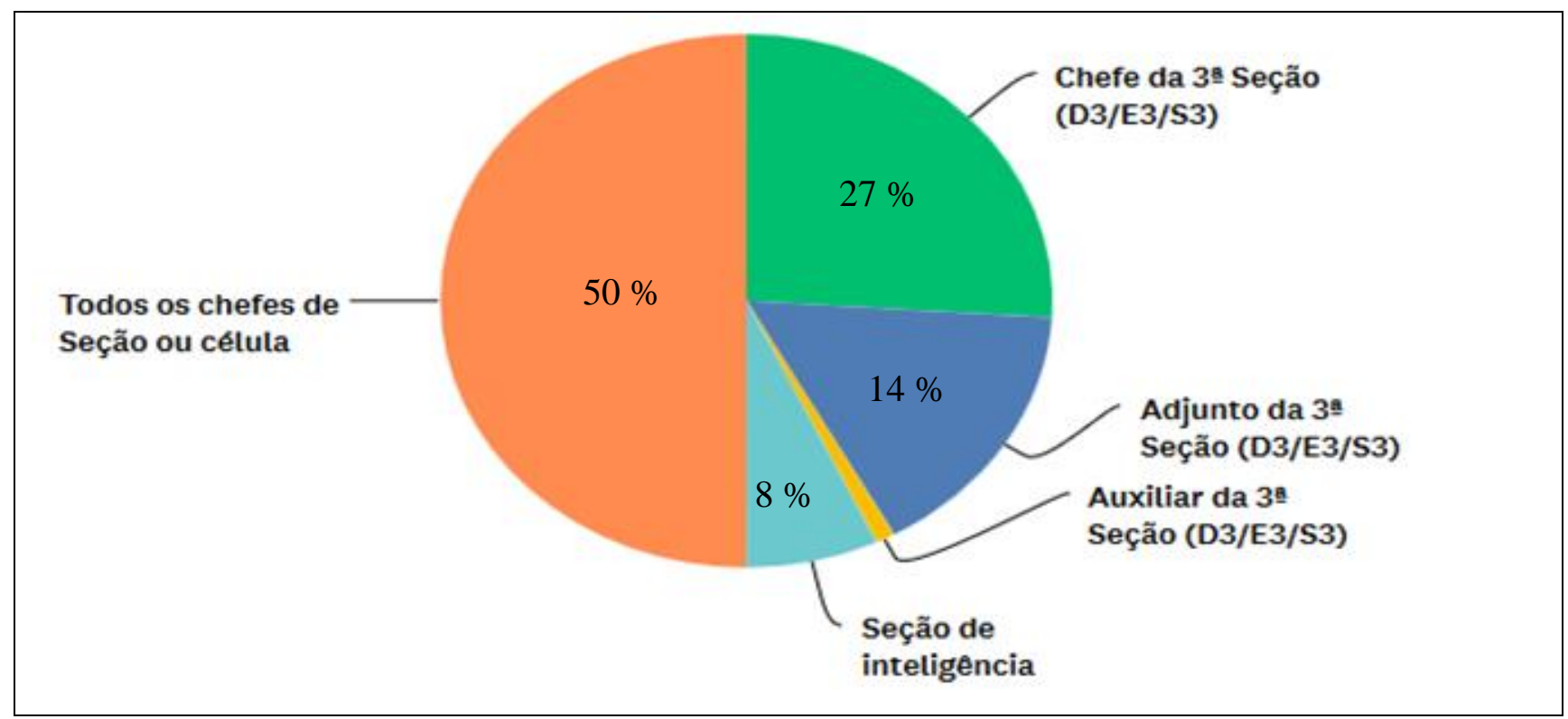

Fonte: o autor.

Desta forma, esta pesquisa contribui para alertar o Exército Brasileiro sobre a necessidade de implantação sistemática de instruções de quadros para os militares das Organizações Militares e para a necessidade de uso da SADLA nas Escolas de Formação e Aperfeiçoamento de Oficiais e Praças. Ainda, da necessidade de estabelecimento de metas de alimentação do sistema para cada Comando Militar de Área, de modo que ocorra a realização de uma operação de GLO sem a devida alimentação da ferramenta com lições aprendidas e melhores práticas.

\section{CONSIDERAÇÕES FINAIS}

A SADLA é uma ferramenta de gestão do conhecimento importante para o Exército Brasileiro. É fundamental que os seus profissionais sejam estimulados a contribuir com suas experiências.

Destarte, a SADLA se apresenta como uma excelente ferramenta de tecnologia da informação, contribuindo para a formação de um banco de dados de lições aprendidas muito eficiente. No entanto, conclui-se através dos dados apresentados, que além de necessitar de melhor 
A APLICAÇÃO DO FORMULÁRIO DE LIÇÕES APRENDIDAS NAS OPERAÇÕES DE GARANTIA DA LEI E DA ORDEM (GLO).

divulgação para o público interno, a SADLA necessita que os quadros utilizem os seus conhecimentos já implantados para consultas durante as operações de GLO.

É oportuno, destacar que o universo de $92 \%$ dos oficiais e praças consultados na pesquisa realizada, acredita que os conhecimentos lançados na SADLA aumentam a eficiência da tropa durante uma Operação de GLO.

Demonstrou-se que a responsabilidade pelo lançamento dos dados na SADLA deve ser de todos os chefes de célula, após a realização de cada operação de GLO realizada. Para tanto, faz-se necessária a realização da reunião de Análise Pós-Ação (APA), para consolidação dos conhecimentos adquiridos que possam servir como lição aprendida para todo o Exército Brasileiro.

Para que a gestão do conhecimento seja eficiente, é necessário que o COTER estabeleça prazos para análise das propostas de lições aprendidas e possa dar o retorno "feedback" para o militar que realizou a contribuição.

Por fim, é oportuno que o COTER e as OM realizem a ampla divulgação da SADLA para os quadros e que estabeleça como determinação, que a cada operação de GLO realizada, sejam lançadas no sistema as lições aprendidas pela tropa e pelo seu Estado-Maior.

\section{REFERÊNCIAS}

EXÉRCITO BRASILEIRO, COTER. Caderno de Instrução de Análise Pós-Ação (EB70-Cl-11.413). Edição Experimental, 2017.

FUZZI, Ludmila Pena. 0 que é pesquisa de campo. 2004. Disponível em: <http://profludfuzzimetodologia.blogspot.com/2010/03/o-que-e-pesquisa-de-campo.html>. Acesso em: 29 out.2018.

GIL, A. C. Métodos e técnicas de pesquisa social. São Paulo: Atlas, 1999.

MINISTÉRIO DA DEFESA, Estado Maior Conjunto das Forças Armadas. Doutrina de Operações Conjuntas (Portaria Normativa no 3810/MD - MD30-M-01), 1ำ volume, 2011.

MINISTÉRIO DA DEFESA, Exército Brasileiro. Instruções Gerais para o Sistema de Doutrina Militar Terrestre -SIDOMT (EB10-IG-01.005), 5a Edição, 2017.

Doutrinário e Lições Aprendidas (EB70-IR-10.007), 3a Edição, 2017 
MINISTÉRIO DA DEFESA, Exército Brasileiro. Sistemática de Acompanhamento Doutrinário e Lições Aprendidas (SADLA). 2018. Disponível em: <http:// www.eb.mil.br/web/guest/todos-os-avisos/asset_publisher/nElT00TYrefc/content/id/8891646>.

Acesso em: 24 jun.2018.

. Manual Estado-Maior e Ordens, 1ㅇv volume, 2ª Edição, 2003.

. Manual Estado-Maior e Ordens, 2o volume, 2a Edição, 2003.

NONAKA, I.; TAKEUCHI, H. Criação de conhecimento na empresa. 19. ed. Rio de Janeiro: Elsevier, 1997.

Criação de conhecimento na empresa. Porto Alegre: Bookman, 2008.

PROBST, G.; RAUB, S.; ROMHARDT. K. Gestão do conhecimento: os elementos construtivos do sucesso. Porto Alegre: Bookman, 2002.

SCATOLIN, Henrique Guilherme. A gestão do conhecimento nas organizações: o legado de Nonaka e Takeuchi. São Paulo, 2015. 